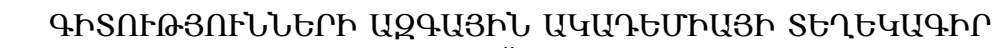

ИЗВЕСТИЯ НАЦИОНАЛЬНОЙ АКАДЕМИИ НАУК АРМЕНИИ

Utipuúplum

74 , № 3,2021

Механика

УДК 539.3

Doi- http://doi.org/10.33018/74.3.4

\title{
HYBRID OF SURFACE SHEAR WAVES AT THE CONTACT INTERFACE BETWEEN PIEZOELECTRIC AND ELECTRICALLY CONDUCTIVE HALF-SPACES
}

\begin{abstract}
Avetisyan Ara S., Gevorgyan A.V., Avetisyan L.V.
Keywords: piezoelectric, perfect conductor, surface shear wave, electro active wave, magneto active wave, wave dispersion, Alfven velocity.

Гибрид поверхностных волн сдвига на гра ᄀнице раздела пьезоэлектрического и элек $т$ ропроводящего полупространств

\author{
Аветисян Ара С., Геворкян А.В., Аветисян Л.В.
}

Ключевые слова: пьезоэлектрик, идеальный проводник, поверхностная волна сдвига, электро активная волна, магнето активная волна, дисперсия волн, скорость Аьлфена.

Аннотация: Рассматривается совместное распространение электро-магнето активных, поверхностных волн упругого сдвига в двухслойном композите. Композит состоит из пьезоэлектрического и идеально проводящего полупространств, и размещен в параллельном поверхности раздела полупространств внешнем постоянном магнитном поле. Сформулирована математическая краевая задача. Анализ полученного дисперсионного уравнения позволяет определить условия существования локализованных поперечных волн на границе раздела двух сред и характер локализаций магнитоупругих и электроупругих волн. Показано, что волновой процесс в композите можно оптимизировать, изменяя напряженность магнитного поля. Наличие параллельного магнитного поля может привести к устранению существующего гибрида поверхностных электроактивных и магнитоактивных упругих поперечных волн или может привести к их возникновению.
\end{abstract}

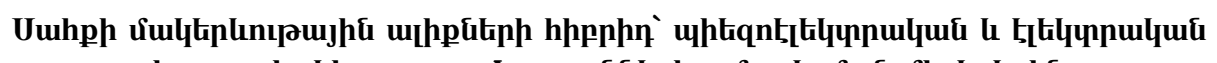

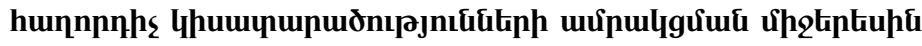

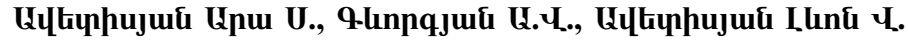

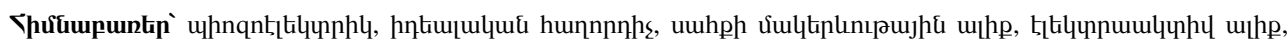

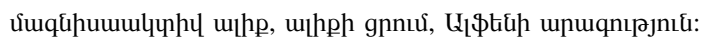

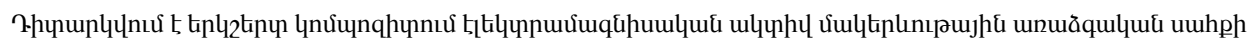

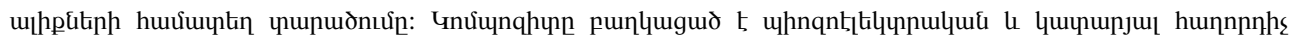

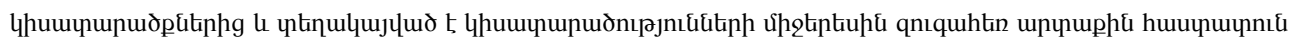

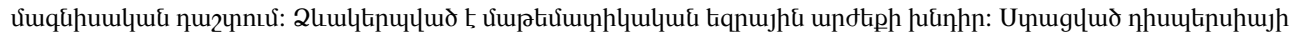

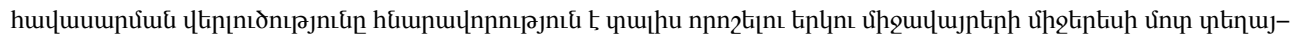

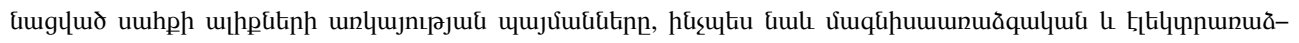

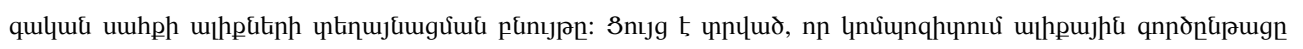


quptip

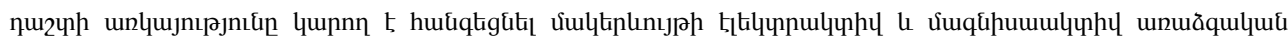

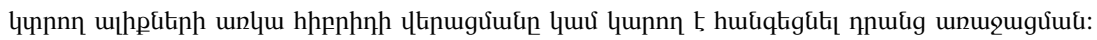

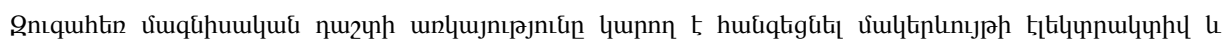

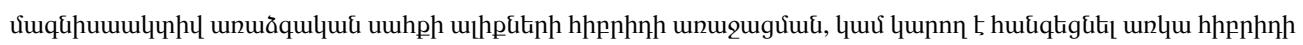
lthumgưuan:

Abstract: The propagation of electro-magnetically active, surface elastic shear waves in a bimaterial composite is considered. The composite consists of the contacting piezoelectric and perfectly conducting half-spaces. There is an external constant magnetic field parallel to the interface of the half-spaces. A mathematical boundary value contact problem is formulated. An analysis of the derived dispersion equation provides the conditions for the existence of surface shear waves localized at the interface between two media. The effects and nature of the localizations of magnetoelastic and electroelastic waves are discussed. It is shown that the wave process in the composite can be optimized by changing the magnetic field intensity. It is shown also that the magnetic field can eliminate the existing hybrid of surface electroactive and magnetically active elastic shear waves, or can lead to their origin.

\section{Introduction}

In [1, 1911 Love A. E. H. showed that, unlike plane strain waves, localization of the wave energy of pure elastic shear is possible in the near-surface zone of an elastic half-space at the junction with a layer of softer material. In 1924, Lord Stoneley R. [2], investigated the possibility of the existence of waves similar to Rayleigh waves and Love waves, which propagate along the inner joints of the layers of the earth's crust. In his work, he also investigated the circumstances under which a Love-type wave can exist if a layer of constant thickness is bounded on both sides by very thick layers of various materials.

In [3], 1968 Bleustein J.L. and in [4, 1969 Gulyaev Yu.V., are showed the possibility of localizing the energy of an electroelastic shear wave near a mechanically free surface of a piezoelectric medium of certain symmetry, under different boundary conditions for the accompanying electric field. After these primary sources, soviet and foreign scientists solved a number of problems on the propagation of electroacoustic waves in piezoelectric crystals and in electrically conductive media, a review of which was given in books [5, 6] already in the eighties. The features of the localization of the wave energy of a purely shear electroelastic wave of the Gulyaev- Bleustein type, in multifunctional media, or in layered composites are still being studied. There are a thousand works where the regularities of the propagation of electroelastic shear waves in composite structures, or in media with complicated properties are investigated.

In modern electronics, inhomogeneous composite (in particular layered, piecewise homogeneous) waveguides are widely used as converters, filters or resonators of electromagneto-acoustic high-frequency wave signals with the use of piezoelectric crystals [7-9], etc.

Qualitatively different interests are represented by the cases when the electroacoustic signal overcomes a transversely inhomogeneous layered structure [10], and when the 
electroacoustic signal flows along the interface of homogeneous layers of the structure [11. In these works, the formation of a hybrid of electroactive waves of elastic shear and elastic plane deformation in the case of non-acoustic contact between layers of piezoelectric materials is investigated.

Naturally, a hybrid of an electroactive elastic shear wave and a magneto active elastic shear wave in a layered composite of a piezoelectric and an electrically conductive material (multifunctional composite material) can provide a peculiar interest. In this case, different surface conditions of mechanical fields at the interface between layers can allow different hybridizations of elastic shear waves.

The proposed work studies the formation and propagation of a hybrid of electroactive and magneto active surface elastic shear waves at the interface between contacting piezoelectric and perfect conducting half-spaces, in an external constant magnetic field parallel to the interface of half-spaces.

\section{Formulation of the mathematical boundary value contact problem}

The composite medium of piezoelectric and electro conductive half-spaces is referred to a rectangular Cartesian coordinate system $0 x_{1} x_{2} x_{3}$. The coordinate plane $0 x_{3} x_{1}$ is the contact interface between half-spaces, the coordinate plane $0 x_{1} x_{2}$ is coincides with the isotropy plane of a $6 \mathrm{~mm}$ piezoelectric medium with hexagonal symmetry. The coordinate axis $0 x_{3}$ is parallel to the polarization axis of the piezoelectric crystal $\bar{p}_{6}$, and the coordinate axis $0 x_{2}$ is directed into the piezoelectric half-space (Fig. 1).

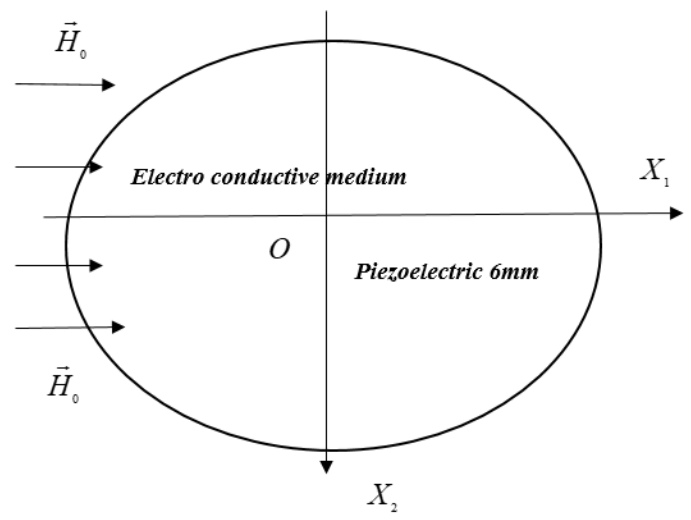

Fig. 1: Located in an external magnetic field $\tilde{\mathbf{H}}_{\mathbf{0}}\left(H_{01}, 0,0\right)$ a composite space consisting of a piezoelectric medium and an perfectly conducting medium

Constant initial magnetic field $\tilde{\mathbf{H}}_{\mathbf{0}}\left(H_{01}, 0,0\right)$ is directed along the axis $0 x_{1}$. The magnetoelasticity equations for a perfectly conducting isotropic medium, in the general 
three-dimensional case, have the form [12]

$$
G_{2} \nabla^{2} \vec{u}^{(2)}+\frac{\mu^{(2)}}{4 \pi}\left\{\vec{\nabla} \times\left[\vec{\nabla} \times \vec{u}^{(2)} \times \tilde{\mathbf{H}}_{\mathbf{0}}\right]\right\} \times \tilde{\mathbf{H}}_{\mathbf{0}}=\rho^{(2)} \frac{\partial^{2} \vec{u}^{(2)}}{\partial t^{2}}
$$

The coupled equations of elasticity and the equations of electrodynamics for a dielectric piezoelectric medium and material relations have the form [5, 6]

$$
\begin{gathered}
\frac{\partial \hat{\sigma}_{i j}^{(1)}}{\partial x_{j}}=\rho^{(1)} \frac{\partial^{2} u_{i}^{(1)}}{\partial t^{2}}, \\
\frac{\partial^{2} E_{i}^{(1)}}{\partial x_{k}^{2}}-\frac{\partial^{2} E_{i}^{(1)}}{\partial x_{i} \partial x_{k}}=\frac{\mu^{(1)}}{c_{0}^{2}} \cdot \frac{\partial^{2} D_{i}^{(1)}}{\partial t^{2}}, \quad \frac{\partial D_{i}^{(1)}}{\partial x_{i}}=0 . \\
\sigma_{i j}^{(1)}=\hat{C}_{i j k l} u_{k l}^{(1)}-e_{m i j} E_{m}^{(1)}, \quad D_{i}^{(1)}=e_{i k l} u_{k l}^{(1)}+\varepsilon_{i j} E_{j}^{(1)} .
\end{gathered}
$$

In equations $(1.1) \div(1.4)$, the indices $i, j, k, l, m \in\{1,2,3\}, G_{2}$ is the shear elastic modulus of the conducting medium, $\rho^{(1)}$ and $\rho^{(2)}$ are the bulk densities of materials, $\vec{u}^{(n)}=\left\{u_{i}^{(n)}\left(x_{1}, x_{2}, x_{3}, t\right)\right\}$ are the vectors of elastic displacements, $\mu^{(1)}$ and $\mu^{(2)}$ are the magnetic fields permeability in piezoelectric and electrically conductive media, respectively. $\hat{C}_{i j k l}$ is a tensor of elastic constants, $\hat{e}_{m i j}$ is a tensor of piezoelectric modules, $\hat{\varepsilon}_{i k}$ is a tensor of dielectric constant of piezoelectric, and $\hat{u}_{i j}=\partial u_{i} / \partial x_{j}+$ $\partial u_{j} / \partial x_{i}$ is the tensor of linear deformation of piezoelectric medium.

Hereinafter, the permeability of the magnetic field of the piezoelectric will be considered $\mu^{(1)}=1$.

The superscripts (1) and (2) denote the quantities corresponding to the piezoelectric half-space and perfect conducting half-space, respectively.

Since the electroactive elastic shear wave is possible in the sagittal plane $0 x_{1} x_{2}$ of a piezoelectric material, the displacement field can be represented by two-dimensional equations in the plane $0 x_{1} x_{2}$ in the half-spaces $n \in\{1,2\}$.

Elastic displacements field of this type is permissible if, in the solutions of equations (1.2) and (1.3), we put $E_{3}^{(1)}\left(x_{1}, x_{2}, t\right) \equiv 0$ taking into account the material relations (1.4).

Then, an electric field is potential also in a piezoelectric medium $\vec{E}^{(1)}\left(x_{1}, x_{2}, t\right)=$ $-\operatorname{grad} \varphi^{(1)}\left(x_{1}, x_{2}, t\right)$. For piezoelectric half-space under consideration, we obtain the following system of equations

$$
\begin{aligned}
& c_{1}^{2} \nabla^{2} u_{3}^{(1)}\left(x_{1}, x_{2}, t\right)=\frac{\partial^{2} u_{3}^{(1)}\left(x_{1}, x_{2}, t\right)}{\partial t^{2}} \\
& \nabla^{2}\left[u_{3}^{(1)}\left(x_{1}, x_{2}, t\right)-\left(e_{15} / \varepsilon_{11}\right) \cdot \varphi^{(1)}\left(x_{1}, x_{2}, t\right)\right]=0
\end{aligned}
$$

Where, $c_{1}=\sqrt{G_{1} / \rho^{(1)}}$ is the speed of the volume shear wave, $G_{1}=C_{44}\left(1+\chi^{2}\right)$ is the piezoelectrically stiffened elastic shear modulus, $\chi=\sqrt{e_{15}^{2} /\left(\varepsilon_{11} C_{44}\right)}$ is the coefficient of electromechanical coupling in piezoelectric medium.

For a magneto active elastic shear wave travelling in perfect conducting half-space, 
from equation (1.1) we obtain

$$
\left(c_{2}^{2}+a_{2}^{2}\right) \frac{\partial^{2} u_{3}^{(2)}\left(x_{1}, x_{2}, t\right)}{\partial x_{1}^{2}}+c_{2}^{2} \frac{\partial^{2} u_{3}^{(2)}\left(x_{1}, x_{2}, t\right)}{\partial x_{2}^{2}}=\frac{\partial^{2} u_{3}^{(2)}\left(x_{1}, x_{2}, t\right)}{\partial t^{2}} .
$$

Here $c_{2}=\sqrt{G_{2} / \rho^{(2)}}$ is the velocity of the bulk shear wave and $a_{2}=H_{0} / \sqrt{4 \pi \rho^{(2)}}$ is the speed of Alfven in a conducting medium.

Since the accompanying magnetic field is neglected in a piezoelectric medium, and the accompanying electric field is neglected in a perfect conducting media, the electroelasticity equations (1.5) in the piezoelectric media and the equation (1.6) of magnetoelasticity in the perfect conducting media can be obtained in a rather simplified form.

Accordingly, they will be small of the order $\approx 10^{-5}$.

The boundary conditions can be also simplified. Taking into account that the corresponding component of the Maxwell stress tensor is identically zero at the interface, $x_{2}=0$ we obtain

$$
\begin{gathered}
C_{44} \frac{\partial u_{3}^{(1)}\left(x_{1}, x_{2}, t\right)}{\partial x_{2}}+e_{15} \frac{\partial \varphi^{(1)}\left(x_{1}, x_{2}, t\right)}{\partial x_{2}}=G_{2} \frac{\partial u_{3}^{(2)}\left(x_{1}, x_{2}, t\right)}{\partial x_{2}}, \\
u_{3}^{(1)}\left(x_{1}, x_{2}, t\right)=u_{3}^{(2)}\left(x_{1}, x_{2}, t\right), \quad \varphi^{(1)}\left(x_{1}, x_{2}, t\right)=0 .
\end{gathered}
$$

The condition (1.7) is obtained from the condition of continuity of mechanical stresses. The conditions (1.8) are obtained from the condition continuity of elastic displacements and the tangential component of the electric field at the interface of the half-planes.

Since we consider the surface waves, the conditions of disturbances attenuation for damping of disturbances over the depth of half-spaces must be satisfied also

$$
\lim _{x_{2} \rightarrow+\infty} u_{3}^{(1)}\left(x_{1}, x_{2}, t\right)=0, \lim _{x_{2} \rightarrow+\infty} \varphi^{(1)}\left(x_{1}, x_{2}, t\right)=0, \lim _{x_{2} \rightarrow-\infty} u_{3}^{(2)}\left(x_{1}, x_{2}, t\right)=0 .
$$

\section{Formation of the hybrid of the electroactive and the magneto active $\mathrm{SH}$ elastic waves}

Based on attenuation conditions (1.9), the solutions both of the equations (1.5) and (1.6) can be represented as

$$
\begin{aligned}
u_{3}^{(1)}\left(x_{1}, x_{2}, t\right)= & A_{1} \cdot \exp \left(-k \alpha_{1} x_{2}\right) \cdot \exp \left[i k\left(x_{1}-\mathrm{v} t\right)\right] \\
\varphi^{(1)}\left(x_{1}, x_{2}, t\right)= & {\left[B_{1} \cdot \exp \left(-k x_{2}\right)-\left(e_{15} / \varepsilon_{11}\right) \cdot A_{1} \cdot \exp \left(-k \alpha_{1} x_{2}\right)\right] \cdot \exp \left[i k\left(x_{1}-\mathrm{v} t\right)\right] } \\
& u_{3}^{(2)}\left(x_{1}, x_{2}, t\right)=A_{2} \cdot \exp \left(k \alpha_{2} x_{2}\right) \cdot \exp \left[i k\left(x_{1}-\mathrm{v} t\right)\right]
\end{aligned}
$$


Here $\alpha_{1}^{2}=1-\mathrm{v}^{2} / c_{1}^{2}>0$ and $\alpha_{2}^{2}=1+a_{2}^{2} / c_{2}^{2}-\mathrm{v}^{2} / c_{2}^{2}>0$ are attenuation coefficients of waves in half-spaces, $\mathrm{v}(\omega)=\omega / k$ is the unknown phase velocity of a surface hybrid wave localized at the contact interface of the adjacent half-spaces of the composite media.

Substituting solutions (2.1) into boundary conditions (1.7) and (1.8), we obtain a system of homogeneous algebraic equations for arbitrary constant amplitudes. From the condition for the existence of nontrivial solutions to a system of homogeneous algebraic equations, the dispersion equation is obtained

$$
\left(1-\mathrm{v}^{2}(\omega) / c_{1}^{2}\right)^{1 / 2}+\left(G_{1} / G_{2}\right) \cdot\left(1+a_{2}^{2} / c_{2}^{2}-\mathrm{v}^{2}(\omega) / c_{2}^{2}\right)^{1 / 2}=\chi^{2}
$$

The condition for the existence of real roots for the dispersion equation (2.3) is $\mathrm{v}^{2}(\omega)<\min \left\{c_{1}^{2}, c_{2}^{2}+a_{2}^{2}\right\}$.

The left side of equation (2.3) is a monotonically decreasing function of the phase velocity $\mathrm{v}(\omega)$. This makes it possible to obtain the conditions for the existence of a hybrid of surface waves depending on the ratio of the shear wave velocities in the media and on the magnetic field intensity. Let's consider different cases:

i) Let the speed of an elastic transverse wave in the piezoelectric medium be less than the speed of an elastic transverse wave in the perfect conducting medium $c_{1} \leq c_{2}$. Since the parameter on the right-hand side of Eq. (2.3) must be between the extreme values of the function on the left-hand side of the Eq. (2.3). The condition for the existence of surface waves in this case can be written in the following form

$$
\left(G_{1} / G_{2}\right) \cdot\left(1+\left(a_{2}^{2}-c_{1}^{2}\right) / c_{2}^{2}\right)^{1 / 2} \leq \chi^{2} \leq 1+\left(G_{1} / G_{2}\right) \cdot\left(1+a_{2}^{2} / c_{2}^{2}\right)^{1 / 2}
$$

Since the coefficient of electromechanical coupling of the piezoelectric medium is less than unity $0<\chi^{2}<1$, the condition (2.4) can be reduced to the form

$$
H_{0} \leq 2 \sqrt{\pi \rho^{(2)}} \cdot\left[\left[\left(G_{2} / G_{1}\right)^{2} \cdot \chi^{4}-1\right] c_{2}^{2}+c_{1}^{2}\right]^{1 / 2}
$$

It follows from this condition that in the absence of an external magnetic field, $\left(H_{01}=0\right)$, the surface elastic shear waves of phase velocity $\mathrm{v}(\omega)<c_{1}$, can exist in the composite if $\chi^{2} \geq\left(G_{1} / G_{2}\right) \cdot \sqrt{c_{2}^{2}-c_{1}^{2}} / c_{2}<1$.

The weak external magnetic field, satisfying to condition (2.5) does not eliminate the surface waves. The strong external magnetic field can lead to elimination of the existing hybrid of surface shear waves, at the following values of the magnetic field intensities

$$
H_{0}>2 \sqrt{\pi \rho^{(2)}} \cdot\left[c_{1}^{2}-\left(1-\chi^{4} G_{1}^{2} G_{2}^{-2}\right) \cdot c_{2}^{2}\right]^{1 / 2}
$$

ii) In velocity ratios $c_{1}^{2} \geq c_{2}^{2}+a_{2}^{2}$, the condition for the existence of a hybrid of surface shear waves can be defined as

$$
\left(1-\left(c_{2}^{2}+a_{2}^{2}\right) / c_{1}^{2}\right)^{1 / 2} \leq \chi^{2} \leq 1+\left(G_{2} / G_{1}\right) \cdot\left(1+a_{2}^{2} / c_{2}^{2}\right)^{1 / 2}
$$

Obviously, in the absence of an external magnetic field, when $H_{01}=0$, for composite materials where $c_{1} \geq c_{2}$ the surface shear waves always exist. Such waves 
can be eliminated outside of the narrow interval of external magnetic field intensities

$$
2 \sqrt{\pi \rho^{(2)}} \cdot\left[\left(1-\chi^{4}\right) \cdot c_{1}^{2}-c_{2}^{2}\right]^{1 / 2} \leq H_{0}<2 \sqrt{\pi \rho^{(2)}} \cdot\left(c_{1}^{2}-c_{2}^{2}\right)^{1 / 2}
$$

iii) When $c_{2}^{2}<c_{1}^{2}<c_{2}^{2}+a_{2}^{2}$, instead of relation (2.7), the existence condition for the surface shear waves can be written as

$$
\left(G_{2} / G_{1}\right) \cdot\left(1-\left(c_{1}^{2}-a_{2}^{2}\right) / c_{2}^{2}\right)^{1 / 2}<\chi^{2}<1+\left(G_{2} / G_{1}\right) \cdot\left(1+a_{2}^{2} / c_{2}^{2}\right)^{1 / 2}
$$

In this case, in the absence of a magnetic field, the condition for of the surface shear wave existence is

$$
\left(1-c_{2}^{2} / c_{1}^{2}\right)^{1 / 2} \leq \chi^{2} \leq 1+\left(G_{2} / G_{1}\right)
$$

The external magnetic field can lead to the elimination of existing surface waves if

$$
H_{0}<2 \sqrt{\pi \rho^{(2)}} \cdot\left[c_{1}^{2}-\left[1-\left(G_{2} / G_{1}\right)^{2} \cdot \chi^{4}\right] c_{2}^{2}\right]^{1 / 2}
$$

From condition (2.10) it follows, that in case of absence of an external magnetic field, shear surface waves always exist.

In the cases both of a weak magnetic field, when $H_{0}<2 \sqrt{\pi \rho^{(2)}} \cdot\left(c_{1}^{2}-c_{2}^{2}\right)^{1 / 2}$ and a strong magnetic field, when $H_{0}>2 \sqrt{\pi \rho^{(2)}} \cdot\left[c_{1}^{2}-\left(1-\chi^{4} G_{1}^{2} G_{2}^{-2}\right) \cdot c_{2}^{2}\right]^{1 / 2}$, the elastic surface shear waves disappears.

An external magnetic field can lead to appearance of waves, if

$$
2 \sqrt{\pi \rho^{(2)}} \cdot\left(c_{1}^{2}-c_{2}^{2}\right)^{1 / 2}<H_{0}<2 \sqrt{\pi \rho^{(2)}} \cdot\left[c_{1}^{2}-\left(1-\chi^{4} G_{1}^{2} G_{2}^{-2}\right) \cdot c_{2}^{2}\right]^{1 / 2}
$$

\section{Numerical Analysis}

For piezoelectric medium, we take the material Cadmium Sulfide CdS, with the following material parameters: $\rho_{1}=4.82 \cdot 10^{3} \mathrm{~kg} / \mathrm{m}^{3}$ - bulk density, $c_{44}=1.43$. $10^{10} \mathrm{~N} / \mathrm{m}^{2}$ - shear modulus, $\chi^{2}=0,047$ - coefficient of electro-mechanical coupling, $G_{1}=1.4972 \cdot 10^{10} \mathrm{~N} / \mathrm{m}^{2}$ - piezoelectrically stiffened elastic shear modulus and $c_{1}=$ $1.7625 \cdot 10^{3} \mathrm{~m} / \mathrm{sec}$ is the speed of bulk shear waves.

For perfect conducting medium we take the material Tin Sn, with material parameters: $\rho_{2}=7,29 \cdot 10^{3} \mathrm{~kg} / \mathrm{m}^{3}$ is the bulk density and $c_{2}=1.7563 \cdot 10^{3} \mathrm{~m} / \mathrm{sec}$ are the shear stiffness of, and the velocity of bulk shear waves is $G_{2}=2.2487 \cdot 10^{10} \mathrm{~N} / \mathrm{m}^{2}$.

For this selected materials $c_{1}>c_{2}$ and the condition for the existence of waves (2.10) is also satisfied. In the absence of an external magnetic field, the surface elastic shear waves propagate in both of half-spaces. In the piezoelectric half-space, the surface shear wave is accompanied by oscillations of the electric field, and in the electro conducting half-space we have a purely elastic shear wave. For the weak magnetic field, when $H_{0}<3.558 \cdot 10^{6} \mathrm{a} / \mathrm{m}$ or strong magnetic field, when $H_{0}>3.797 \cdot 10^{6} \mathrm{a} / \mathrm{m}$, the surface waves in the composite do not exist.

For the intensities of the external magnetic field satisfying to condition (2.12): $3.558 \cdot 10^{6} a / m<H_{0}<3.797 \cdot 10^{6} a / m$, there exist the hybrid both of the magnetically 
active surface elastic shear wave in electro conducting medium and the electrically active surface elastic shear wave in a piezoelectric localized at the contact interface of these media.

\section{Conclusion}

In a composite consisting of $6 \mathrm{~mm}$ class of hexagonal symmetry piezoelectric medium contacting with perfect conducting medium, in the absence of external constant magnetic field the elastic shear surface waves are always exist localizing at contact interface. In the piezoelectric medium, this wave is accompanied by oscillations of the electric field. The presence of an external magnetic field parallel to the interface can eliminate these surface waves.

At other values of the external magnetic field intensities, the hybrid both of a magnetically active elastic surface shear wave in perfect conducting medium and an electrically active elastic shear wave in a piezoelectric medium is exist localized at the contact interface of these media.

This kind of compound composite makes it is possible, by means of changing intensities of external magnetic field, to control propagation modes of electro-magnetoelastic surface waves in composite devises.

\section{References}

[1] Love A. E. H., «Some problems of geodynamics », first published in 1911 by the Cambridge University Press and published again in 1967 by Dover, New York, USA., Chapt 11: Theory of the propagation of seismic waves,

[2] Stoneley R., Elastic Waves at the Surface of Separation of Two Solids, (1924), Proceedings of the Royal Society of London. Series A, Containing Papers of a Mathematical and Physical Character, Volume 106, Issue 738, pp. 416-428, http://doi.org/10.1098/rspa.1924.0079

[3] Bluestein F.L., A new surface wave in piezoelectric materials, Appl. Phys. Lett. (1968), vol.13, №12. pp. 412-413.

[4] Гуляев Ю.В. Поверхностные ультразвуковые волны в твердых телах. - Письма в ЖЭТФ, 1969, т.9, вып.1, с.63-65.

[5] Партон В.З., Кудрявцев Б.А., Электромагнитоупругость пьезоэлектрических и электропроводных тел, 1988, Наука, с.472,

[6] Royer, D., Dieulesaint, E., Elastic Waves in Solids I. Free and Guided Propagation. 2000, Springer, Berlin, p. 293

[7] Mechanics of Composite, Hybrid and Multi-Functional Materials, vol. 5, Proceed. Of the 2018 Annual Conference on Experimental and Applied Mechanics, Editors Piyush R. Thakre, Raman P. Singh, G. Slipher, 
[8] Mechanics of Composite, Hybrid and Multi-Functional Materials, vol. 6, Proceed. Of the 2020 Annual Conference on Experimental and Applied Mechanics, Editors Raman P. Singh, V. Chalivendra,

[9] Mechanics of Composite and Multi-Functional Materials, vol. 6, Proceed. Of the 2017 Annual Conference on Experimental and Applied Mechanics, Editors Piyush R. Thakre, Raman P. Singh, G. Slipher,

[10] Avetisyan A.S., Khachatryan V.M., Propagation of Hybrid Electroelastic Waves in Transversally Inhomogeneous Periodic Piezoelectric Structure, (2020), Mechanics. Proc. of NAS of Armenia, 73 (1). pp. 6-22, http://doi.org/10.33018/73.1.1

[11] Avetisyan Ara S., Jilavyan Hakob S., Hybrid of Rayleigh and Gulyaev-Bluestein Electro-Acoustic Waves Near the Inner Surface of a Layered Piezoelectric Composite, Mechanics, Proceed. of NAS RA, (2020), vol. 73, №2, pp. 10-30, http://doi.org/10.33018/73.2.2

[12] Gevorgyan A.V., Avetisyan A.S., About surface waves at the interface between the half-spaces of piezoelectric and electrically conductive materials, In Proc. «Investigations on Mechanics of Deformable Solid », Yerevan, (1983), pp. 77-83 (in Russian)

Геворкян А.В., Аветисян А.С., О поверхностных волнах на граᄀнице раздела

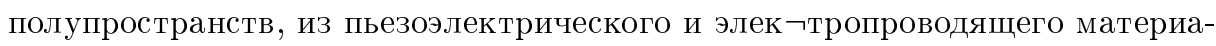
лов, Сб. статьей "Исследования по механике твердого деформируемого тела", Ереван, 1983, стр.77-83.

Dedicated to the memory of our Teacher: To Professor Mels Vagharshak Belubekyan

\section{Information about authors:}

Avetisyan Ara S. - Department of Dynamics of Deformable Systems and Coupled Fields, Institute of Mechanics of NAS of Armenia, E: mail-ara.serg.avetisyan@gmail.com,

Gevorgyan Artak V. - Department of Dynamics of Deformable Systems and Coupled Fields, Institute of Mechanics of NAS of Armenia, E: mail-AGevorgyanV@gmail.com,

Avetisyan Levon V. - Postgraduate in Institute of Mechanics of NAS of Armenia, E: mail-levon.avetisyan1@ysumail.am. 